\title{
L'espace lyrique méditerranéen au Moyen Âge. Nouvelles approches, Sous la direction de Dominique Billy, François Clément et Annie Combes
}

\section{Walter Meliga}

\section{(2) OpenEdition}

\section{Journals}

Edizione digitale

URL: http://journals.openedition.org/studifrancesi/7470

DOI: $10.4000 /$ studifrancesi.7470

ISSN: 2421-5856

\section{Editore}

Rosenberg \& Sellier

\section{Edizione cartacea}

Data di pubblicazione: 1 décembre 2009

Paginazione: 601-602

ISSN: 0039-2944

\section{Notizia bibliografica digitale}

Walter Meliga, «L'espace lyrique méditerranéen au Moyen Âge. Nouvelles approches, Sous la direction de Dominique Billy, François Clément et Annie Combes», Studi Francesi [Online], 159 (LIII | III) | 2009, online dal 30 novembre 2015, consultato il 09 janvier 2021. URL: http://journals.openedition.org/ studifrancesi/7470 ; DOI: https://doi.org/10.4000/studifrancesi.7470

Questo documento è stato generato automaticamente il 9 janvier 2021.

\section{cc) (†) $\odot$}

Studi Francesi è distribuita con Licenza Creative Commons Attribuzione - Non commerciale - Non opere derivate 4.0 Internazionale. 


\title{
L'espace lyrique méditerranéen au
} Moyen Âge. Nouvelles approches, Sous la direction de Dominique Billy, François Clément et Annie Combes

\author{
Walter Meliga
}

\section{NOTIZIA}

L'espace lyrique méditerranéen au Moyen Âge. Nouvelles approches, Sous la direction de Dominique BILLY, François CLÉMENT et Annie COMBES, Toulouse, Presses Universitaires du Mirail, 2006 («Interlangues»), pp. 301.

1 La raccolta di contributi che forma il volume si pone sotto il segno dell'interdisciplinarità e dell'ampiezza geografica: attorno al nucleo dello «spazio lirico» medievale si trovano infatti a discutere studiosi di diversa specializzazione (letteratura, linguistica, storia, musicologia) su soggetti che riguardano l'Occidente cristiano, la Spagna musulmana ed ebraica, la cultura araba. Il Mediterraneo è lo spazio geografico che unisce le diverse esperienze e che consente uno scambio continuo fra di esse (a correzione, almeno parziale, della celebre tesi di Henri Pirenne sulla frattura consumatasi fra le sue sponde dopo la conquista araba di quella meridionale).

2 Il volume si divide in tre sezioni, per un totale di quindici contributi, che si elencano qui di seguito. Nella prima sezione intitolata «Le Poète et la Cour» trovano posto $\mathrm{i}$ contributi di: Gérard GOUIRAN, Chercher et faire fortune en Italie: Falquet de Romans sur les traces de Raimbaut de Vaqueiras; Michelle szKILNIK, Des princes poètes dans les romans français des XII' et XIII' siècles; François CLÉMENT, Le métier de poète dans l'Occident musulman; Martin AURELL, "Fin'amor, wadd" et féodalité dans la lyrique des troubadours; Abdellatif GHOUIRGATE, Un trio célèbre dans l'Andalus du XI' siècle. Nella seconda sezione, «Du jardin au je lirique», troviamo: Mercedes BREA, L'Hortus conclusus dans la poésie lyrique des 
troubadours; Annie COMBES, La reverdie: des troubadours aux romanciers arthuriens, les métamorphoses d'un motif; Cynthia RoBinson, Les lieux de la lyrique: l'incarnationnisme dans la lyrique mystique andalouse; Roberto ANTONELLI, Le je lyrique dans la poésie méditerranéenne; Arie SCHIPPERS, Le thème de l'amour dans la poésie strophique hébraïque au Moyen Âge en Espagne musulmane: Moïse ibn Ezra (1055-1138) et Abraham ibn Ezra (1090-1165). Nella terza sezione, «Traditions formelles et musicales»: Elizabeth AUBREY, La langue musicale de dévotion: les 'cantigas de loor' et les chansons de Guiraut Riquier; Antoni RosselL, Les "Cantigas de Santa Maria": stratégie et composition, de l'élément métrique à lélément idéologique; Dominique BILLY, Les influences galégo-portugaises chez Cerveri de Girona; Anna ALBERNI, Deux 'albas' catalanes anonymes du XIV siècle; Peter T. RICKETTS, L'influence de la culture arabe sur le lexique de l'ancien occitan, en particulier dans le domaine musical. 